EGU2020-17914

https://doi.org/10.5194/egusphere-egu2020-17914

EGU General Assembly 2020

(c) Author(s) 2021. This work is distributed under

the Creative Commons Attribution 4.0 License.

\title{
Braided rivers networks dynamics: analyzing topographic data from a large flume experiment
}

\author{
Daniel Papa ${ }^{1}$ and Christophe Ancey ${ }^{2}$ \\ ${ }^{1}$ EPFL-ENAC-LHE, Lausanne, Switzerland (danielvito.papazang@epfl.ch) \\ ${ }^{2}$ EPFL-ENAC-LHE, Lausanne, Switzerland (christophe.ancey@epfl.ch)
}

Braided rivers are highly dynamical systems characterized by varying network-like structures even under quasi-steady conditions. Understanding their dynamics is crucial in geomorphology and river engineering (e.g., river restoration in Alpine and piedmond streams). Open questions about these dynamics include the definition and quantitative description of bed equilibrium. Here we propose to tackle this problem using a new method based on graph theory. This algorithm, called low-path allows one to extract the network structure of a braided river from its Digital Elevation Model (DEM). It is then possible to quantify and analyse the dynamics of the braided system, and not just the bed evolution, as has been done in earlier studies. To assess the dynamics and equilibrium of a braided river, we study two runs representing two distinct phases of the same braided river: the transition from a single channel to a braided river (run 1) and the equilibrium state of this river (run 2). A set of control parameters was used to characterise both runs and supplement the low-path method. We find that although a clear distinction can be made between straight channel and braided channel for both methods, it is more difficult to distinguish between transitional braided and equilibrium braided rivers. Finally we propose a set of dimensionless numbers that specify the braided network and can be used with numerical or stochastic simulations of a braided network. To illustrate their utility, we apply the Low Path method to a real Alpine braided river (the River Navisence, Wallis, Switzerland) and compare the results to our experimental data. 